\title{
A STUDY ON THE DEMOGRAPHIC AND CLINICAL PROFILE OF WHEEZING IN THE FIRST YEAR OF LIFE
}

KEY WORDS: Wheezing,

Viral Respiratory Tract Infection, Ante Natal and Neonatal Care, Recurrence

\section{Dr Sunita Das}

Dr Deshish Kumar Panda Dr Kedarnath Das Dr Saiprasanna Behera*
Senior resident, Santha Bhima Bhoi Medical College \&Hospital,Balangir. Odisha - 767001

Asst. Prof in Paediatrics, Santha Bhima Bhoi Medical College \& Hospital, Balangir. Odisha - 767001

Associate Professor of Department of Paediatrics, SCB Medical College and Hospital, Cuttack, Odisha-753007

Research Associate, CRO Pharmatrendz Private Limited. Bhubaneswar. Odisha-751014. *Corresponding Author

This hospital based observational cross sectional study having a sample size of 100 was undertaken at S.C.B. Medical College and S.V.P.P.G.I.P., Cuttack, with an objective to study the clinical profile and risk factors for wheezing in infancy from November 2018 to November 2020.

Wheezing is accountable for a high demand of medical consultations and emergency care services with relatively high rates of hospitalization. In this study, several risk factors were identified for wheezing in less than one year of age which had little resemblance to similar studies made in various other age groups. However, maternal smoking as a risk factor could not be found in our study due to social cultural lifestyle in the study population. Factors like caesarean section, history of birth asphyxia, NICU admissions and living in kuccha house were not found to impose risk for wheezing in infancy in the study in contrary to similar such studies in other age groups. The present study revealed, that among all other etiology, the viral respiratory tract infections including bronchiolitis was the most common cause of wheezing in infancy (64\%) followed by WALRI (wheeze associated lower respiratory tract infection). In conclusion, if an infant with wheezing has risk factors like male sex, preterm, more than six months age, family history of atopy or repeated upper respiratory tract illness or overcrowding in family, anticipating the severity recurrence should be suspected. These infants should be monitored closely for signs of clinical deterioration.

Proper health education, ante natal and neonatal care, promoting of breast feeding and creating awareness to the public regarding modifiable risk factors like separation of family members having upper respiratory illness from young infants will reduce the severity of wheezing and will help prevent their recurrence to much extent.

\section{INTRODUCTION :-}

Wheezing in children is a common problem owing to unique age specific, anatomic and physiologic properties of the lung. Approximately 25 to $30 \%$ of infants have at least one wheezing episode ${ }^{1}$. A wheeze is defined as a continuous high pitched sound emitting from chest during expiration which lasts for more than 250 micro seconds ${ }^{72}$. Recurrent wheezing is defined as three or more episodes of parentally reported wheezing over a 12 month period ${ }^{1}$. Most common causes of wheezing include allergies, infections, gastro intestinal reflux disease and obstructive sleep apnea. Less common causes include congenital abnormalities, foreign body aspiration and cystic fibrosis.

Family history, age at onset, pattern of wheezing, seasonality, suddenness of onset and association with feeding, cough, respiratory illness and positional changes help in diagnosis of wheezing. A focused examination and targeted diagnostic testing guided by clinical suspicion also provides useful information. In a study in UK, the relative importance of low birth weight, preterm birth, low maternal age, household size, exposure to maternal smoking, early termination of breast feeding and socio economic status in the etiology of wheezing in the first few years of life was evaluated in 15712 children. The independent determinants of wheezing were male sex, maternal smoking during pregnancy and low birth weight.

Wheezing in infants has been hypothesized to be a risk factor for the future development of recurrent wheeze, but epidemiological and clinical studies have been inconclusive. Also, it is not yet clear what roles genetic predisposition and environmental or other risk factors may play in wheezing and its future development of asthma. Although asthma may originate soon after birth, the natural history of the disease is not understood very well ${ }^{3}$. Many infants have episodes of wheezing associated with viral respiratory illnesses ${ }^{4}$. So, this study is undertaken at Srirama Chandra Bhanja (S.C.B.) Medical College and hospital and Sardar Vallabhbhai Patel Post Graduate Institute of Pediatrics (S.V.P.P.G.I.P.) Cuttack, to get a better picture regarding wheezing in less than one year of age.

\section{MATERIALS AND METHODS :-}

The present study was reviewed by the Institutional Ethics Committee of SCB Medical College and Hospital, Cuttack. Odisha. India. All babies less than 1 year of age diagnosed to have wheezing attending to pediatric department in S.C.B. Medical College and S.V.P.P.G.I.P., Cuttack have been evaluated by collecting their base line data, clinical evaluation and investigations.

Period of study: November 2018 to November 2020

Study design: A hospital based observational cross sectional study. Sample size: Sample size for the cross sectional prevalence study was calculated using the formula sample size $(n)=4 \mathrm{PQ} / \mathrm{l}^{2}$ with a prevalence $(p)$ of wheezers in less than 1 year of age 46 percent $^{69}$ (as per previous studies done in this place.) Minimum sample size was 95 . A sample of 100 has been taken for convenience.

Sampling method: The study was performed as per the proforma drafted for study on wheezing in infancy. The history and clinical findings are recorded in details. The routine investigations were done and special investigations were performed wherever necessary. The post treatment outcome was documented. The details of cases were drawn as master chart with record of the relevant findings.

\section{Inclusion Criteria:}

1. Babies till one year of age. 
2. Babies with clinically documented wheezing

3. Babies whose parents gave consent for the study

\section{Exclusion criteria:}

1. Babies with wheezing in more than one year of age.

2. Babies with foreign body aspiration.

3. Babies whose parents did not give consent for the study.

All the data collected was tabulated and statistically analyzed to draw the final conclusion.

\section{RESULT \& DISCUSSION :-}

All the infants, diagnosed to have wheeze attending to the pediatric department of S.C.B. Medical College and S.V.P.P.G.I.P., Cuttack were evaluated during November 2018 to November2020. Their baseline data was collected, clinical evaluation and investigation was performed.

Total 100 infants were enrolled who were diagnosed to have wheeze.

There was no mortality reported in our study. Out of the 100 cases studied, majority of them were male $(61 \%)$ and remaining female (39\%). Majority of them were from Eastern Odisha.

Table 1: Distribution based on distribution of gender

\begin{tabular}{|l|l|l|}
\hline Sex & Number & Percentage \\
\hline Male & 61 & 61 \\
\hline Female & 39 & 39 \\
\hline Grand total & 100 & 100 \\
\hline
\end{tabular}

From the above table, it was seen that wheezing was significantly more frequent in boys than girls as the boys tend to have lower airway function than girls during infancy and childhood $^{56}$. In the line with the published literature, we also found higher number of male infants $(61 \%)$ with recurrent wheezing as compared to female infants (39\%). Our finding is also supported by Neto et al who reported male gender as a risk factor.

Antenatal history was uneventful in all the subjects. $90 \%$ of babies were full term, however only $10 \%$ babies were preterm. Out of the 100,89 were delivered by normal delivery and 11 by LSCS. NICU admissions were required only in 4 $(4 \%)$ out of 100 infants. Birth asphyxia history was absent in $93 \%$ of patients however respiratory distress and MAS was seen in $5 \%$ and $2 \%$ of the cases respectively.

Table 2: Distribution based on birth history

\begin{tabular}{|l|l|l|}
\hline Birth history & Number & Percentage \\
\hline Term & 90 & 90 \\
\hline Pre term & 10 & 10 \\
\hline Grand total & 100 & 100 \\
\hline
\end{tabular}

Table 3: Distribution based on type of delivery

\begin{tabular}{|l|l|l|}
\hline Mode of delivery & Number & Percentage \\
\hline LSCS (Caesarean Section) & 11 & 11 \\
\hline Normal & 89 & 89 \\
\hline Grand total & 100 & 100 \\
\hline
\end{tabular}

From Table number 3 , it is quite clear that the caesarean section did not have a role in wheezing as per our study.

Table No 4: Distributions based on NICU admissions

\begin{tabular}{|l|l|l|}
\hline NICU Admissions & Number & Percentage \\
\hline Yes & 4 & 4 \\
\hline No & 96 & 96 \\
\hline Grand total & 100 & 100 \\
\hline
\end{tabular}

Table No 4 clarifies that the NICU admissions did not possess a threat for wheezing in infancy, as per this study.

Table No 5: Distribution based on birth asphyxia

\begin{tabular}{|l|l|l|}
\hline MAS/ Birth Asphyxia & Number & Percentage \\
\hline Respiratory distress & 5 & 5 \\
\hline
\end{tabular}

\begin{tabular}{|l|l|l|}
\hline MAS & 2 & 2 \\
\hline No & 93 & 93 \\
\hline Grand Total & 100 & 100 \\
\hline
\end{tabular}

In our study, maximum cases (93\%) had no history of birth asphyxia. Thus, perinatal asphyxia is not considered as a risk factor for wheezing in infancy.

In 8 infants who developed recurrent wheeze, there was no history of assisted delivery, NICU admissions or birth asphyxia. However we found preterm delivery is a risk factor for recurrent wheezing (Relative risk -3)

(95CI:0.38-23.68) had it is three times more common in preterminfants

Table No 6: Recurrence of wheeze according to birth history

\begin{tabular}{|l|l|l|l|l|l|}
\hline \multirow{2}{*}{$\begin{array}{l}\text { Birth } \\
\text { history }\end{array}$} & \multicolumn{4}{|l|}{ Recurrence of wheeze } & Grand \\
\cline { 2 - 6 } & Yes & $\%$ & No & $\%$ & 10 \\
\hline Preterm & 2 & 20 & 8 & 80 & 10 \\
\hline Full term & 6 & 6.7 & 84 & 93.3 & 90 \\
\hline Grand total & 8 & 8 & 92 & 92 & 100 \\
\hline
\end{tabular}

$P$ value- 0.35, relative risk-3 (95 CI: 0.38-23.68) Chi-Square applied.

In our study, majority of infants were having breastfeeding (88\%). Mean time of weaning was 6.78 months.

\section{Table No 7: Distribution based on breast feeding}

\begin{tabular}{|l|l|l|}
\hline \multicolumn{1}{|c|}{ Breast feeding } & Number & Percentage \\
\hline Yes & 88 & 88 \\
\hline No & 12 & 12 \\
\hline Grand total & 100 & 100 \\
\hline
\end{tabular}

In our study maximum cases (88\%) were breast feeding, while only $12 \%$ were on exclusive top feeding.

Rusconi et al. found an independent protective effect of prolonged breast feeding against early transient wheeze, but not persistent wheeze or wheeze of late onset. However, Oddy et al. found that the age of introduction of non-breast milk was inversely associated with several asthma outcomes at 6 years of age ${ }^{68}$.

In the ALSPAC cohort, infants who were breastfed in the first 6 months were less likely to wheeze in the first 6 months than bottle-fed infants. However, there was no evidence for any long term protection conferred by breast milk on wheeze.

In the literature, connection between family history and wheezing is well reported. A family history of atopy is a risk factor for all types of wheezing. Maternal atopy in particular increases the risk of persistent wheezing. Family studies have demonstrated the genetic contribution to atopy, persistent wheezing and asthma. The familial contribution to transient and early wheezing is likely to take the form of congenitally small airways. Infants having family history have three times more risk of developing recurrent wheezing . (Relative risk 3. 17 (95 CI:0.50-20.53) (RR-1.11)..

A number of published genetic studies have confirmed earlier epidemiological findings of a preferential maternal transmission; however others have failed to replicate this finding $^{62,63}$.

In our studies we evaluated the various risk factors for atopy, asthma and smoking. In our study 24 infants had a family history of either atopy or asthma. Of these maternal history of smoking was absent. Out of those 24,4 had recurrent wheezing $(16.67 \%)$, whereas 76 infants who had no family history, 4 (5.26\%) infants had recurrent wheezing. 
Table No 8: Distribution based on risk factors in the family

\begin{tabular}{|l|l|l|}
\hline Parameter & Number & Percentage \\
\hline Atopy & 11 & 11 \\
\hline Asthma & 13 & 13 \\
\hline Maternal Smoking & 0 & 0 \\
\hline
\end{tabular}

Our study revealed, 11\% cases had family history of atopy while $13 \%$ had a family history of asthma. However, maternal smoking history was absent in all the cases.

Table No 9: Recurrence of wheeze according to family history

\begin{tabular}{|c|c|c|c|c|c|}
\hline \multirow{2}{*}{$\begin{array}{c}\text { Family } \\
\text { history }\end{array}$} & \multicolumn{4}{|c|}{ Recurrence of wheeze } & Grand \\
\cline { 2 - 5 } & yes & $\%$ & no & $\%$ & total \\
\hline Yes & 4 & 16.7 & 20 & 83.3 & 24 \\
\hline No & 4 & 5.3 & 72 & 94.7 & 76 \\
\hline Grand total & $\mathbf{8}$ & $\mathbf{8}$ & $\mathbf{9 2}$ & $\mathbf{9 2}$ & $\mathbf{1 0 0}$ \\
\hline
\end{tabular}

$P$ value -0.23 (NS), Relative risk - 3.17 (95 CI:0.50-20.53) ChiSquare test is applied.

Table 10: Recurrence of wheeze according to family history of atopy

\begin{tabular}{|c|c|c|c|c|c|}
\hline Family history & \multicolumn{3}{|c|}{ Recurrence of wheeze } & Grand \\
of atopy & yes & $\%$ & no & $\%$ & total \\
\hline Yes & 4 & 16.7 & 20 & 83.3 & 24 \\
\hline No & 4 & 5.3 & 72 & 94.7 & 76 \\
\hline Grand total & $\mathbf{8}$ & $\mathbf{8}$ & $\mathbf{9 2}$ & $\mathbf{9 2}$ & $\mathbf{1 0 0}$ \\
\hline
\end{tabular}

$P$ value -0.23 (NS), relative risk -3.17 (95 CI: 0.50-20.53) Chi -Square is applied

In a study by Simon in 372 US children, $128(34.4 \%)$ experienced transient wheezing and 175 (47\%) never wheezed. Author in his study had found that atopy was not associated with transient wheezing. Boys were more likely to be transient wheezers. Transient wheeze was associated with antibiotic treatment in the first 6 months of life. Author had also confirmed that transient wheezing in young children was not associated with an atopic pre disposition ${ }^{64}$.

In a study by Rusconi, in 16,333 Italian children, there was a stronger $(p<0.0001)$ positive association between personal history of asthma or allergic rhinitis and persistent and late onset wheezing than transient early wheezing.

Maternal smoking in pregnancy is a risk factor for all types of wheezing but not for asthma itself. It increases the risk of transient early wheezing and impaired lung function in infancy $^{65}$. It appears to affect lung development, resulting in reduced lung capacity and smaller airways, as well as prematurity and low birth weight. But in our study, there is no maternal history of smoking in our cases.

In our study, average family size was around 4 members. We found no significant difference between wheezers and nonwheezers with respect to number of family members (4 and above) $(p>0.05)$. However, all eight infants who developed recurrent wheezing had a family size of 4 members, indicating that overcrowding is associated with recurrent wheezing.

Table No 11: Recurrence of wheeze according to over crowding

\begin{tabular}{|c|c|c|c|c|c|}
\hline \multirow{2}{*}{$\begin{array}{c}\text { Family } \\
\text { members }\end{array}$} & \multicolumn{4}{|c|}{ Recurrence of wheeze } & Grand \\
\cline { 2 - 5 } total
\end{tabular}

$P$ value-0.98(NS), Chi-Square is applied.

We found no significant difference between wheezers and non- wheezers with respect to kuccha and pucca house ( $p>$
0.05). All 8 children who developed recurrent wheezing had pucca house indicating that type of house (kuccha house) is not a risk factor for recurrent wheezing.

Table No 12: Recurrence of wheeze according to type of house

\begin{tabular}{|c|c|c|c|c|c|}
\hline \multirow{2}{*}{ House type } & \multicolumn{4}{|c|}{ Recurrence of wheeze } & \multirow{2}{*}{$\begin{array}{c}\text { Grand } \\
\text { total }\end{array}$} \\
\cline { 2 - 5 } & Yes & $\%$ & No & $\%$ & 10 \\
\hline Kuccha & 0 & 0 & 10 & 100 & $\mathbf{1 0}$ \\
\hline Pucca & 8 & 8.9 & 82 & 91.1 & $\mathbf{9 0}$ \\
\hline Grand total & $\mathbf{8}$ & $\mathbf{8}$ & $\mathbf{9 2}$ & $\mathbf{9 2}$ & $\mathbf{1 0 0}$ \\
\hline
\end{tabular}

$P$ value-0.6 (NS), Chi-Square test is applied.

In our study, bronchiolitis was diagnosed in $33 \%$ infants followed by WALRI (29\%), broncho pneumonia (22\%); bronchopneumonia with CHD (8\%), lobar pneumonia (3\%), WALRI with CHD (3\%) andWALRI with measles (2\%).

Table No 13: Distribution based on diagnosis

\begin{tabular}{|c|c|c|}
\hline Diagnosis & Number & Percentage \\
\hline WALRI & 29 & 29 \\
\hline WALRI with CHD & 3 & 3 \\
\hline WALRI with Measles & 2 & 2 \\
\hline Bronchiolitis & 33 & 33 \\
\hline Bronchopneumonia & 22 & 22 \\
\hline Bronchopneumonia with CHD & 8 & 8 \\
\hline Lobar pneumonia & 3 & 3 \\
\hline Total & 100 & 100 \\
\hline
\end{tabular}

In our study, maximum cases of infant wheezers were diagnosed as bronchiolitis (33\%) followed by WALRI (wheeze associated lower respiratory tract infection).

In a study by Rattanadilok et al in children under 5 years old, bronchiolitis and pneumonia accounted for 55\% and $40.6 \%$ of lower respiratory tract infection with wheezing. Most of the patients 162 out of 251 (64\%) cases were children under 2 years old. The wheezing symptom declined significantly in children older than 4 years of age. Lower respiratory tract infection with wheezing was found all year around but was more frequent in the rainy season similar to other respiratory infections ${ }^{61}$.

\section{CONCLUSION:}

In conclusion, if an infant with wheezing has risk factors like male sex, preterm, more than six months age, family history of atopy or repeated upper respiratory tract illness or overcrowding in family, anticipating the severity; recurrence should be suspected. These infants should be monitored closely for signs of clinical deterioration.

Proper health education, ante natal and neonatal care, promoting of breast feeding and creating awareness to the public regarding modifiable risk factors like separation of family members having upper respiratory illness from young infants will reduce the severity of wheezing and will help prevent their recurrence to much extent.

\section{REFERENCES:}

1) Martinez FD, Wright AL, Taussig LM, Holberg CJ, Halonen M, Morgan WJ, Group Health Medical Associates. Asthma and wheezing in the first six years of life. New England Journal of Medicine. 1995 Jan 19;332(3):133-8.

2) Reisman JJ, Canny GJ, Levison H. Wheezing in infants and young children. Childhood asthma.New York: Marcel Dekker. 1993:255-82.

3) Martinez FD. The origins of asthma and chronic obstructive pulmonary disease in early life. Proceedings of the American Thoracic Society. 2009 May $1 ; 6(3): 272-7$.

4) Wright AL, Holberg CJ, Martinez FD, Morgan WJ, Taussig LM. Breast feeding and lower respiratory tract illness in the first year of life. Group Health Medical Associates. British Medical Journal. 1989 Oct 14;299(6705):946-9.

5) Halonen M, Stern D, Taussig LM, Wright A, Ray CG, Martinez FD. The predictive relationship between serum IgE levels at birth and subsequent incidences of lower respiratory illnesses and eczema in infants. American Review of Respiratory Disease. 1992 Oct 1;146:866-.

6) Martinez FD, Morgan WJ, Wright AL, Holberg CJ, Taussig LM, Group Health Medical Associates' Personnel*. Diminished lung function as a predisposing factor for wheezing respiratory illness in infants. New England Journal of Medicine. 1988 Oct 27;319(17):1112-7. 
7) Finder JD. Understanding airway disease in infants. Current problems in pediatrics. 1999 Mar 1;29(3):65-81.

8) Schwartz J, Gold D, Dockery DW, Weiss ST, Speizer FE. Predictors of asthma and persistent wheeze in a national sample of children in the United States. Am Rev Respir Dis. 1990;142(3):555-62.

9) Martinez FD, Cline M, Burrows B. Increased incidence of asthma in children of smoking mothers. Pediatrics. 1992 Jan 1;89(1):21-6.

10) Pattenden S, Antova T, Neuberger M, Nikiforov B, De Sario M, Grize L, Heinrich J, Hruba F, Janssen N, Luttmann-Gibson H, Privalova L. Parental smoking and children's respiratory health: independent effects of prenatal and postnatal exposure. Tobacco control.2006 Aug 1;15(4):294-301.

11) Fergusson DM, Horwood LJ, Shannon FT. Parental smoking and respiratory illness in infancy. Archives of disease in childhood. 1980 May 1;55(5):358-61.

12) Leung $A K$, Kellner JD, Davies HD. Respiratory syncytial virus bronchiolitis. Journal of the National Medical association.2005 Dec;97(12):1708.

13) Sporik R, Holgate ST, Cogswell JJ. Natural history of asthma in childhood-a birth cohort study. Archives of disease in childhood. 1991 Sep 1;66(9):1050-3.

14) Forastiere F, Agabiti N, Corbo GM, Dell'Orco V, Porta D, Pistelli R, Levenstein S, Perucci CA. Socioeconomic status, number of siblings, and respiratory infections in early life as determinants of atopy in children. Epidemiology. 1997 Sep 1:566-70.

15) Tager IB, Hanrahan JP, Tosteson TD, Castile RG, Brown RW, Weiss ST, Speizer FE. Lung function, pre-and post-natal smoke exposure, and wheezing in the first year of life. American Journal of Respiratory and Critical Care Medicine. 1993 Apr; 147(4):811-7.

16) Clarke JR, Salmon B, Silverman M. Bronchial responsiveness in the neonatal period as a risk factor for wheezing in infancy. American journal of respiratory and critical care medicine. 1995 May; 151 (5):1434-40.

17) Camilli A, Holberg C,Wright A, Taussig L. Group Health Medical Associates. Parental childhood respiratory illness and respiratory illness in their infants. Pediatr Pulmonol. 1993;16:275-80.

18) Sears MR, Greene JM, Willan AR, Wiecek EM, Taylor DR, Flannery EM, Cowan JO, Herbison GP, Silva PA, Poulton R. A longitudinal, population-based, cohort study of childhood asthma followed to adulthood. New England Journal of Medicine.2003 Oct 9;349(15):1414-22.

19) Visser CA, Garcia Marcos L, Eggink J, Brand PL. Prevalence and risk factors of wheeze in Dutch infants in their first year of life. Pediatric pulmonology. 2010 Feb;45(2):149-56.

20) Urkin J, Ishay Y, Bilenko N, Bar-David Y, Gazala E, Mijalovsky A, Lapidus V. Night-time cough in children with acute wheezing and with upper respiratory tract infection. Primary Care Respiratory Journal.2008 Dec;17(4):217-21.

21) Stein RT, Sherrill D, MorganWJ, Holberg CJ, Halonen M, Taussig LM,Wright AL, Martinez FD. Respiratory syncytial virus in early life and risk of wheeze and allergy by age 13 years. The Lancet. 1999 Aug 14;354(9178):541-5.

22) Oddy WH, Holt PG, Sly PD, Read AW, Landau LI, Stanley FJ, Kendall GE, Burton PR. Association between breast feeding and asthma in 6 year old children: findings of a prospective birth cohort study. Bmj. 1999 Sep 25;319(7213):815

23) Meher BK, Pradhan DD, Pradeep S, Das L, Beriha SS, Panigrahi S. Factors influencing age of onset of wheezing among children with recurrent wheezing and the association of Vitamin D status with atopic manifestations. Indian Journal of Allergy, Asthma and Immunology. $2017 \mathrm{Jul}$ 1;31 (2):76.

24) Florin TA, Plint AC, Zorc JJ. Viral bronchiolitis. The Lancet. 2017 Jan 14;389(10065):211-24.

25) Kliegman RM, St Geme J. Nelson textbook of pediatrics 21 st edition. Elsevier. 2019 . 